University of Massachusetts Amherst ScholarWorks@UMass Amherst

Resource Economics Department Faculty

Publication Series

Resource Economics

2009

\title{
An experimental investigation of endowment source heterogeneity in two-person public good games
}

J Spraggon

RJ Oxoby

Follow this and additional works at: https://scholarworks.umass.edu/resec_faculty_pubs

\section{Recommended Citation}

Spraggon, J and Oxoby, RJ, "An experimental investigation of endowment source heterogeneity in two-person public good games" (2009). Economics Letters. 147.

Retrieved from https://scholarworks.umass.edu/resec_faculty_pubs/147 inclusion in Resource Economics Department Faculty Publication Series by an authorized administrator of ScholarWorks@UMass Amherst. For more information, please contact scholarworks@library.umass.edu. 


\title{
An experimental investigation of endowment source heterogeneity in two-person public good games ${ }^{\text {tr }}$
}

\author{
John Spraggon ${ }^{\mathrm{a}, *}$, Robert J. Oxoby ${ }^{\mathrm{b}, 1}$ \\ a Department of Resource Economics, University of Massachusetts Amherst, 80 Campus Center Way, Amherst, MA, 01003, USA \\ b Department of Economics, University of Calgary, 2500 University Drive NW, Calgary Alberta, Canada T2N 1N4
}

\section{A R T I C L E I N F O}

Article history:

Received 5 March 2008

Received in revised form 7 April 2009

Accepted 8 April 2009

Available online 17 April 2009

Keywords:

Public goods

Found money

Heterogeneity

Experiments

JEL classification

C9

D63

H4

J15

\section{A B S T R A C T}

We find an "inverse found money effect" in two-person public good experiments in which individuals earning their endowments contribute more and engage in "altruistic conditional cooperation" when they are matched with those whose endowment is provided by the experimenters.

Published by Elsevier B.V

\section{Introduction}

The role of asset legitimacy in experimental environments is both nuanced and context dependent. For example, Cherry et al. (2002) demonstrate how the presence of found money (or legitimizing assets) affects behavior in dictator games: legitimizing first-movers' rights to assets (i.e., making first-movers' endowments earned rather than found money) significantly increased self-interested behavior predicted by standard models of wealth maximization. Oxoby and Spraggon (2008) show that asset legitimacy affects not only firstmovers, but also second-movers (i.e., receivers) in dictator games: legitimizing receivers' claim to assets resulted in dictators extending larger offers (i.e., greater than 50\%). However, in public good games (Clark, 2002; Cherry et al., 2005) find no found money effect, although Harrison (2007) re-analyzes Clark's (2002) data and concludes that

\footnotetext{
We thank the Social Science and Humanities Research Council of Canada, the Canadian Institute for Advanced Research, and the Institute for Advanced Policy Analysis for financial support.

* Corresponding author. Tel.: +1 413545 6651; fax: +1 4135455853.

E-mail addresses: jmspragg@resecon.umass.edu (J. Spraggon), oxoby@ucalgary.ca (R.J. Oxoby).

1 Tel.: +14032202586
}

'house money' significantly increases the propensity to free-ride but not the level of contribution. Kroll et al. (2007) suggests that found money effects are more important in the best-shot public good environments which is more asymmetric than the standard linear public good.

Here, we conduct a two-person public good game with heterogeneity in the source of participants' endowments in an effort to more directly identify the effects of such heterogeneity on behavior. In our experiment some participants earned their wealth to be used in the game while others had it allocated to them by the experimenter. We identify an "inverse found money effect" in which participants who earned their endowments and were matched with someone who did not were more unconditionally and conditionally cooperative. Thus, in our environment the found money effect described in the mental accounting literature (Thaler, 1999) and experimentally identified by, among others, Cherry et al. (2002) is reversed. We attribute this result to 'anticipatory reciprocity' as discussed by Cherry et al. (2005) and Kroll et al. (2007).

\section{Experimental design}

We use a two-person public good game and the strategy method to analyze the effect of found money and heterogeneity of endowment 
source on unconditional and conditional contributions. This provides the simplest environment to investigate the importance of this heterogeneity. ${ }^{2}$ In our experiment each individual $i \in\{1,2\}$ made contribution decisions $c_{i} \in\left[0, \omega_{i}\right]$, given her endowment $\omega_{i} \in\{10,20,30\}$. Individuals were randomly paired and individuals' payoff functions were given by $^{3}$

$\Pi_{i}\left(c_{i}, c_{j}\right)=\left(\omega_{i}-c_{i}\right)+0.75\left(c_{i}+c_{j}\right), \quad i \neq j$.

Our primary treatment variable was the sources of endowments: participants were randomly assigned to either an allocated endowment or received their endowment based on their performance on a 15 minute, 12 question exam consisting of GMAT questions. Thus, these individuals earned an endowment based on their score: \$10 if they answered between zero and five questions correctly, \$20 if they answered between six and nine questions correctly, and $\$ 30$ if they answered ten or more questions correctly. Individuals assigned to an allocated endowment were randomly given either $\$ 10, \$ 20$, or $\$ 30$.

Participants were informed of their endowment, that of the individual with whom they were matched, and whether or not this person had earned or been allocated their endowment. Individuals were asked to make their contributions using the strategy vector method (Fischbacher et al., 2001; Keser and van Winden, 2000) in which they chose an unconditional contribution $c_{i}^{U} \in\left[0, \omega_{i}\right]$ and a set of conditional contributions $c_{i}^{C}\left(c_{j}^{U}\right)$ indicating how much they would contribute given each possible unconditional contribution of the person with whom they were matched. In determining payoffs, one individual in each pair was randomly chosen and her unconditional contribution was implemented; the other individuals' appropriate conditional contribution was implemented and payoffs were paid in accordance with Eq. (1).

In this design there are three possible types of pairs: both individuals were allocated endowments (Endowed groups), both individuals earned their endowments (Earned groups), and groups in which one individual earned her endowment and the other individual was allocated an endowment (Mixed groups). Similarly, an individual could have been one of four types based on the source of her endowment and that of the person with whom she was matched. We denote these types in terms of "source of own endowment/source of other's endowment": Endowed/Endowed, Endowed/Earned, Earned/ Endowed, or Earned/Earned. Additionally, note that there may be wealth differences within each group which potentially affect contribution decisions (Buckley and Croson, 2006; Isaac and Walker, 1988).

\section{Results}

One hundred and forty subjects from the undergraduate student body at the University of Calgary participated in the experiment, each earning between $\$ 7.00$ and $\$ 42.00$ (average $\$ 18.10$ ). The experiments were conducted using computers and were programmed in $z$-Tree (Fischbacher, 2007). ${ }^{4}$

Summary statistics are presented in Table 1. Percent aggregate contribution (i.e., implemented unconditional contribution $c_{i}^{U}$ plus the conditional contribution $c_{j}^{C}\left(c_{i}^{U}\right)$ as a percentage of the total wealth of the dyad $\omega_{i}+\omega_{j}$ ) was $32.35 \%$ for the Endowed, $36.35 \%$ for the Mixed and $40.50 \%$ for the Earned groups. These are in line with the contribution range expected in linear public good games (Zelmer,

\footnotetext{
2 Other experiments using two-person public good games include Goeree et al. (2002, who focus on increasing group size while holding MPCR constant), Harrison and Hirshleifer (1989), and Botelho et al. (2005). Fundamentally a two-person public good game is a prisoners' dilemma game and we refer the reader to Camerer (2003), Sally (1995), and Ledyard (1995) for reviews.

${ }^{3}$ We used a high efficiency factor $(0.75)$ so that the marginal gain of all individuals within a group contributing was consistent with that found in more standard fourperson public good experiments (0.4)

4 The instructions and treatment files are available upon request.
}

Table 1

Summary statistics.

\begin{tabular}{lcc}
\hline & Percent aggregate contribution & Percent contribution \\
\hline Endowed/Endowed & $32.35 \%$ & $37.92 \%$ \\
& $(6.18 \%)$ & $(5.06 \%)$ \\
Endowed/Earned & $n=18$ & $n=36$ \\
& $36.35 \%$ & $28.83 \%$ \\
& $(4.20 \%)$ & $(4.41 \%)$ \\
Earned/Endowed & $n=37$ & $n=37$ \\
& $36.35 \%$ & $55.81 \%$ \\
Earned/Earned & $(4.20 \%)$ & $(6.01 \%)$ \\
& $n=37$ & $n=37$ \\
& $40.50 \%$ & $46.83 \%$ \\
& $(7.75 \%)$ & $(5.84 \%)$ \\
& $n=15$ & $n=30$ \\
\hline
\end{tabular}

Table 2

Regressions analysis.

\begin{tabular}{lcc}
\hline & Percent contribution & Percent conditional contribution \\
\hline Constant & $0.273^{*}$ & -0.072 \\
& 0.161 & 0.086 \\
Other percent contribution & & $0.919^{* * *}$ \\
& & 0.042 \\
Other percent contr ${ }^{2}$ & & $-0.420^{* * *}$ \\
& & 0.041 \\
Endowed/Endowed & 0.030 & 0.030 \\
& 0.138 & 0.074 \\
Earned/Endowed & $0.332^{* *}$ & $0.168^{* *}$ \\
& 0.140 & 0.075 \\
Earned/Earned & 0.280 & 0.142 \\
& 0.201 & 0.108 \\
Wealth & 0.004 & -0.009 \\
& 0.014 & 0.007 \\
Other wealth & 0.009 & $0.014^{* * *}$ \\
Treatment*wealth & 0.006 & 0.003 \\
& -0.002 & -0.0004 \\
Number of obs. & 0.006 & 0.003 \\
Prob> $\chi^{2}$ & 140 & 2350 \\
\hline
\end{tabular}

* indicates significance at the $10 \%$ level, $* *$ at the $5 \%$ level and *** at the $1 \%$ level.

2003) and are not statistically different from each other using either standard parametric or non-parametric tests ( $p>0.2$ for all tests).

However, this lack of statistical difference at the aggregate level masks important differences at the individual level. Unconditional contributions range from a low of $28.83 \%$ for Endowed/Earned participants to a high of $55.81 \%$ for Earned/Endowed participants. We investigate these differences using OLS, the results of which are presented in the Percent Contribution column of Table $2 .{ }^{5}$ Notice that this regression indicates that those in the Earned/Endowed treatment contribute a significantly higher percentage of their wealth than those in the Endowed/Earned treatment. ${ }^{6}$

We read this as strong evidence for the anticipatory reciprocity hypothesis put forth by Cherry et al. (2005) and Kroll et al. (2007). When subjects who earn their endowment are matched with those who do not, those who earned their endowment contribute more and those who were given their endowment contribute less.

Our data also shows that, at least with two players, heterogeneity in endowment source does not lead to lower contributions to the

\footnotetext{
5 Our regression model is

$c_{i}^{U} / \omega_{i}=\alpha+\beta_{1}$ (Endowed $/$ Endowed $)+\beta_{2}$ (Earned / Endowed $)$

$$
\left.+\beta_{3} \text { (Earned } / \text { Earned }\right)+\beta_{4} \omega_{i}+\beta_{5} \omega_{j}+\beta_{6} \text { Treatment* } \omega_{i}+\varepsilon_{i} \text {. }
$$
}

Tobit analysis, as well as including dummy variables for the different wealth levels, other wealth levels yield identical results.

${ }^{6}$ In contrast to Harrison (2007) we find that endowed (both Endowed/Earned and Endowed/Endowed) are more likely to completely free-ride than subjects who earn their endowment. Nevertheless, excluding those who contribute zero from our regression yields identical results. 


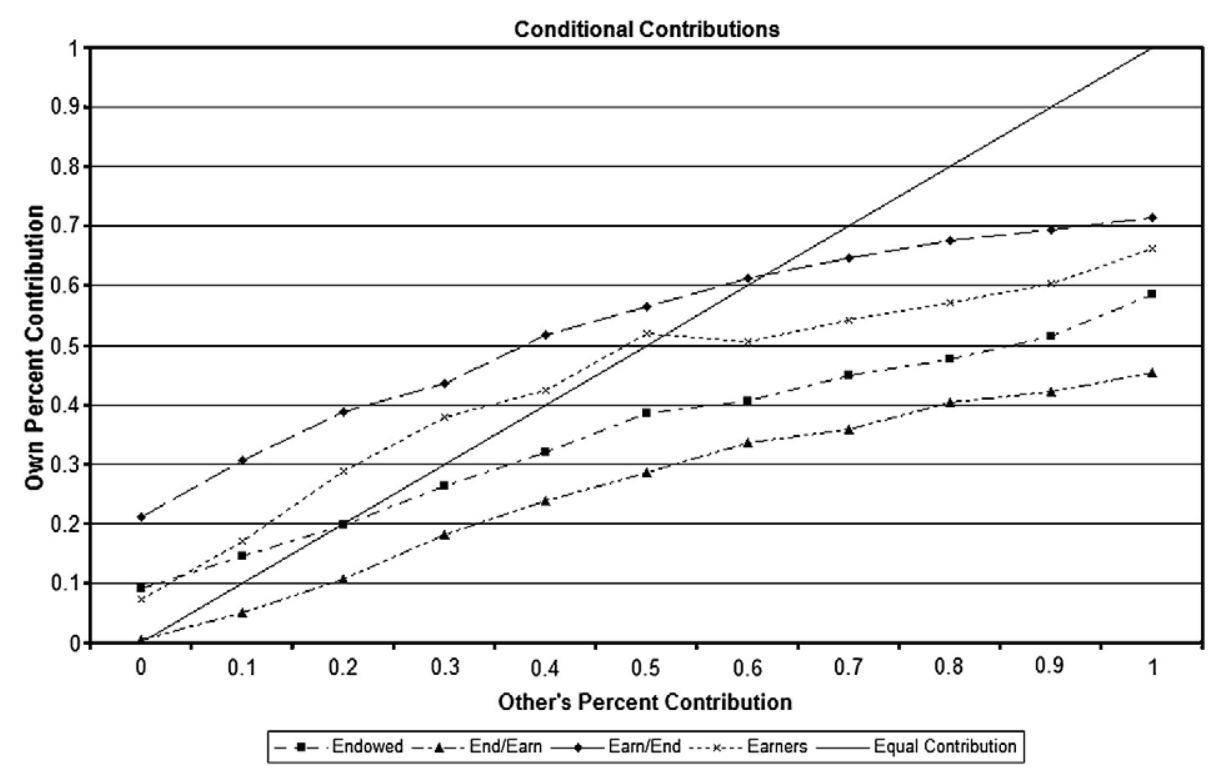

Fig. 1. Average conditional contributions by type.

public good, as suggested by other research (Alesina et al., 1999; Alesina and Ferrara, 2000; Poterba, 1997). The reason for this is perhaps counterintuitive: Those who earn their endowments contribute enough to the public good to offset the reduced contributions of those whose endowment is allocated.

Turning to our data on conditional contributions $c_{j}^{C}\left(c_{i}^{U}\right)$, for each subject $i$ we have a vector of length $\omega_{j}$ detailing their conditional contribution given each of the possible contributions of the person with whom they are matched. We transform this into a percentage conditional contribution given the percentage contribution of the other subject, $c_{j}^{C}\left(\frac{c_{i}^{U}}{\omega_{i}}\right) / \omega_{j}$, the means of which are presented in Fig. 1.

Our data shows that those earning their wealth are "altruistic conditional cooperators" in that they always chose to contribute a greater percentage than that of their partner when that individual was allocated her wealth. On the other hand, when participants with an allocated level of wealth were paired with participants who earned their wealth, they chose conditional contributions below that of the person with whom they were paired.

The Percent Conditional Contribution column of Table 2 suggests that the differences observed in Fig. 1 are statistically significant, using a linear regression allowing for individual random effects. ${ }^{7}$ The regression suggests that Earned/Endowed subjects contribute significantly more than Endowed/Earned subjects. ${ }^{8}$

Fig. 1 suggests that those earning their wealth are more conditionally cooperative than those whose wealth was allocated. Earned/Endowed subjects choose to contribute a greater percentage than their partner up to $60 \%$, Earned/Earned subjects contribute more up to $50 \%$, Endowed/Endowed only contribute more than their partner when the other's contributions are below $20 \%$ of their wealth and Endowed/Earned contribute less for all levels of their partners

\footnotetext{
${ }^{7}$ Our regression model is

$c_{j}^{C}\left(c_{i}^{U} / \omega_{i}\right) / \omega_{j}=\alpha+\beta_{1} c_{j} / \omega_{j}+\beta_{2}\left(c_{j} / \omega_{j}\right)^{2} \beta_{3}$ (Endowed / Endowed $)$

$+\beta_{4}($ Earned $/$ Endowed $)+\beta_{5}($ Earned $/$ Earned $)+\beta_{6} \omega_{i}$

$+\beta_{7} \omega_{j}+\beta_{8}$ Treatment* $\omega_{i}+v_{i}+\varepsilon_{i j}$.
}

Treatment variable crossed with other percent contribution, other percent contribution squared, percent wealth and other percent wealth were dropped due to insignificance. A Tobit regression on this model provided identical results.

8 Again, if we exclude those who contribute zero from our regression as in Harrison (2007) the results are identical. contribution on average. Thus, those who earned their endowment, and are matched with someone who does not, are more conditionally cooperative than those who were allocated their endowment. This result is also consistent with the idea of "anticipatory reciprocity" (Cherry et al., 2005; Kroll et al., 2007) if earners expect non-earners will contribute.

\section{Conclusions}

We report the results from one-shot, two-player public good games where individuals were either endowed (from the experimenter) or earned (via a short exam) their wealth and then made unconditional and conditional contributions. Strikingly, we find a reversal of the effect suggested by the mental accounting literature (Thaler, 1999) and supported experimentally in dictator games by authors such as Cherry et al. (2002) regarding found money effects: We find that individuals who earned their wealth and were matched with someone who was endowed with their wealth contributed significantly more than those who were endowed with their wealth and who were matched with someone who earned their wealth. Moreover, we find that not only are the unconditional contributions higher among earners matched with those who are endowed but their conditional contributions are significantly higher as well. This inverse found money effect is consistent with the anticipatory reciprocity effect discussed in Cherry et al. (2005) and Kroll et al. (2007). Subjects who earn their endowment seemed to expect those who were endowed with it to contribute more and as a result they contribute more themselves.

\section{References}

Alesina, A., Ferrara, E., August 2000. Participation in heterogeneous communities. Quarterly Journal of Economics 115 (3), 847-904.

Alesina, A., Baqir, R., Easterly, W., November 1999. Public goods and ethnic divisions. Quarterly Journal of Economics 114 (4), 1243-1284.

Botelho, A., Harrison, G., Hirsch, M., Rutström, E., 2005. Bargaining behavior demographics and nationality: what can the experimental evidence show? Field Experiments in Economics 10, 337-372.

MayBuckley, E., Croson, R., 2006. Income and wealth heterogeneity in the voluntary provision of linear public goods. Journal of Public Economics 90 (4-5), 935-955.

Camerer, C.F., 2003. Behavioral Game Theory. Princeton University Press, Princeton NJ

Cherry, T.L., Frykblom, P., Shogren, J.F., 2002. Hardnose the dictator. American Economic Review 92 (4), 1218-1221.

Cherry, T.L., Shogren, J.F., Kroll, S., 2005. The impact of endowment heterogeneity and origin on public good contributions: evidence from the lab. Journal of Economic Behavior and Organization 57 (3), 357-365. 
Clark, J., 2002. House money effects in public goods experiments. Experimenta Economics 5 (3), 223-232

Fischbacher, U., June 2007. z-Tree: Zurich toolbox for ready-made economic experiments. Experimental Economics 10 (2), 171-178.

Fischbacher, U., Gächter, S., Fehr, E., 2001. Are people conditionally cooperative? Evidence from a public goods experiment. Economics Letters 71, 397-404.

Goeree, J.K., Holt, C.A., Laury, S.K., February 2002. Private costs and public benefits: unraveling the effects of altruism and noisy behavior. Journal of Public Economics 83 (2), 255-276.

Harrison, G.W., 2007. House money effects in public good experiments: comment. Experimental Economics 10 (4), 429-437.

Harrison, G., Hirshleifer, J., 1989. An experimental evaluation of weakest link/best shot models of public goods. Journal of Political Economy 97 (1), 201-225.

Isaac, R., Walker, J., 1988. Group size effects in public goods provision: the voluntary contributions mechanism. Quarterly Journal of Economics 103 (1), 179-199.

Keser, C., van Winden, F., 2000. Conditional cooperation and voluntary contributions to public goods. Scandanavian Journal of Economics 102 (1), 23-39.
Kroll, S., Cherry, T.L., Shogren, J.F., 2007. The impact of endowment heterogeneity and origin on contributions in best-shot public good games. Experimental Economics $10,411-428$

Ledyard, J.O., 1995. Public goods: a survey of experimental research. In: Kagel, J.H., Roth, A.E. (Eds.), Handbook of Experimental Economics. Princeton University Press, New Jersey.

Oxoby, R.J., Spraggon, J., 2008. Mine and Yours: Property Rights in Dictator Games. Journal of Economic Behavior and Organization 65, 703-713.

Poterba, J.M., 1997. Demographic structure and the political economy of public education. Journal of Public Policy and Management 16, 48-66.

Sally, D., 1995. Conversation and cooperation in social dilemmas: a meta-analysis of experiments from 1958 to 1992. Rationality and Society 7 (1), 58.

Thaler, R.H., 1999. Mental accounting matters. Journal of Behavioral Decision Making 12, 183-206.

Zelmer, J., 2003. Linear public goods experiments: a meta-analysis. Experimental Economics 5, 299-310. 